\title{
Menstrual Cycle Pattern among Adolescent School Girls in Chhattisgarh
}

\author{
Priyamvada Srivastava $^{1}$, Aniksha Varoda $^{2}$, Reeta Venugopal $^{3}$
}

\section{ABSTRACT}

Background: The menstrual cycle is a very important indicator of women's reproductive health and of their endocrine function. Menstruation, and the menstrual cycle are characterized by variability in volume, pattern and regularity. The purpose of this study was to determine the age of menarche, source of information regarding menstrual cycle, patterns, and problems faced by the adolescent rural and urban school girls, of Chhattisgarh, during menstruation. Method: The present study was cross-sectional descriptive study carried out on 750 school going adolescent girls from rural and urban areas of Chhattisgarh. For collection of data Self-structured questionnaire based on issues related to menstruation cycle was used. Results: Average age of menarche for overall sample taken, of adolescent girls of Chhattisgarh is 14.33 years. Mean age of menarche for urban and rural adolescent girls. 14.45 years and 13.89 years respectively. The adolescent girls received information about menstrual cycle from various sources viz mother (34.6\%), friends (19.4\%) and sisters (16.8\%). It was noticed that most of the adolescent girls (61.25\%) experienced menstrual problems (59\% urban girls and 64.5\% rural girls reported menstrual problems). $45.6 \%$ of urban girls and 35.4\% rural girls experienced abdominal pain as one of the major problem during menstrual cycle. $16 \%$ \& $20.3 \%$ urban and rural girls reported to suffer from headache during menstrual cycle respectively. During menstrual cycle, fatigue was observed in $17.8 \%$ urban girls and $22.4 \%$ rural girls. $20.6 \%$ and $21.6 \%$ urban and rural girls reported food craving respectively. Higher percentage of rural girls experienced psychological symptoms like depression, anxiety, fatigue, food cravings and headaches, as compared to urban girls. Conclusion : Higher percentage of rural adolescent girls of Chhattisgarh experience problem during menstruation cycle as compared to the urban girls, the percentage of rural girls reporting psychological symptoms during cycle, is higher as compared to urban girls. Intervention program for awareness regarding Menstrual cycle and associated issues for adolescent girls and their parents should be planned so that the problems of the girls can be minimized.

\footnotetext{
${ }^{1}$ Associate Director, Centre for Women’s Studies Pt. Ravishankar Shukla University, Raipur (C.G.), India

${ }^{2}$ Research Assistant, Centre for Women’s Studies Pt. Ravishankar Shukla University, Raipur (C.G.), India

${ }^{3}$ Director, Centre for Women’s Studies Pt. Ravishankar Shukla University, Raipur (C.G.), India

*Responding Author

(C) 2016 I P Srivastava, A Varoda, R Venugopal; licensee IJIP. This is an Open Access Research distributed under the terms of the Creative Commons Attribution License (http://creativecommons.org/licenses/by/2.0), which permits unrestricted use, distribution, and reproduction in any Medium, provided the original work is properly cited.
} 


\section{Menstrual Cycle Pattern among Adolescent School Girls in Chhattisgarh}

Keywords: Age at Menarche, Menstrual Abnormalities, Socio-Economic Class

Adolescence (10-19) is a sensitive period in the life of a girls. It is a period when transition from girlhood to childhood. Around $21.3 \%$ i.e. nearly $1 / 5^{\text {th }}$ of the total population of India is represented by this population Dambhare et al, (2012). This period is marked with on set of menarche. There is major physiological/ physical change in girls for which they should be prepared. As menstruation is normal physiological event which signifies the ability of women for procreation, any disorder during this period should be treated as major gynecological problem in adolescence Verma et al (2011). Reproductive health and endocrine functions are indicated by menstrual cycle. Menstrual cycle can be understood by its volume, pattern and regularity. In a study it was found that menstrual disorder exist around $87 \%$ of the respondents Verma et al (2011). Various types of menstrual disorders are prevalent viz menstrual irregularity, menorrhagia, polymenorrhea, oliomenorrhea, dysmenorrhoea etc. It has been observed that most of the girls face some or the other problem, which are individual specific.

Although it is a physiological process of the body like any other, still many misconception regarding menstrual cycle exist, it is considered as unclean in Indian society. When the physical, physiological and behavioral discomfort joins with the misconception exist in the society, the girls develop negative attitudes towards it, proper information regarding menstrual cycle is not imparted to the girls. Menstrual process and misconception attached to it inhibit girls to discuss regarding menstrual cycle and menstrual problem.

On set of menarche is affected by genetic, ethnic, environmental and nutritional factors and there can be 4-5 years variation, most of the female experience menarche between 10 to 16 year (Thomas et al 2001). Ailbereisen and Karacke, 1996 reported only 5\% of population menarche at before 10 or after 15 years.

Menstrual disorders of various kinds affect not only the adolescence girls but also their family (Adam2002, Diaz 2006 et al ). It is very important to understand the menstrual problem among the adolescence girls so that intervention programme can be organized. Research regarding on set of menarche and menstrual disorder are visible in other countries. In India paucity of research in this area is seen. Hence this study was undertaken (Okusanya et al 2009).

\section{THE AIM AND OBJECTIVES OF THE STUDY}

1. To find out the age of menarche among the Adolescent girls of the Urban and Rural area of Chhattisgarh, India.

2. To study different menstrual patterns.

3. To find out the prevalence and types of menstrual disorders. 


\section{MATERIAL AND METHODS}

Chhattisgarh is a state in Central India. The state was formed on November 1, 2000 by partitioning 16 Chhattisgarhi speaking southeastern districts of Madhya Pradesh. For the present investigation 750 adolescents girls were selected from different schools of Chhattisgarh (Raipur). The data was selected from the age group of 10-18 years. girls willing to participate in the study, after explaining them the aim of the study were included in the study. These subjects were then interviewed face to face in local language (Chhattisgarhi and Hindi) using a pretested semi structured questionnaire after obtaining their informed consent. The questionnaire contained information regarding demographic parameters, socio-economic status, age at menarche, source of pre-menarchial information, menstruation cycle characteristics, total days of bleeding, regularity of cycle and prevalence of menstrual problems etc.

\section{The following definitions were used to describe menstrual cycle disorders:}

- Menstrual syndrome (MS) is recurrent variable cluster of trouble ( physical and emotional symptoms ) that develop prior to and during menstruation and subsides after the cycle. The MS consists of low backache, fatigue, breast heaviness, abdominal bloating, increased weight, headache, irritability, skin disorders, aggressiveness, depression, gastrointestinal symptoms and loss of appetite.

- Dysmenorrhoea defined as Painful cramping abdominal pain accompanying menstruation \& lasting 12- 24 hours severe enough to interfere with normal activities, or require medication.

\section{RESULTS}

\section{Table 1. Mean age of menarche in Urban and Rural Adolescents girls}

\begin{tabular}{|l|l|l|l|}
\hline Age in years & Urban $\mathbf{n - 3 9 4 ( \% )}$ & Rural $\mathbf{n}-\mathbf{3 5 6}(\%)$ & Total $\mathbf{n - 7 5 0}(\mathbf{\% )}$ \\
\hline $\begin{array}{l}\text { Mean age of menarche } \\
\text { in years }\end{array}$ & 14.45 & 13.89 & 14.33 \\
\hline$\leq 11$ & $20(5.0)$ & $10(2.8)$ & $30(4.1)$ \\
\hline 12 to 14 & $253(64.2)$ & $264(74.1)$ & $517(68.9)$ \\
\hline$\geq 15$ & $121(30.7)$ & $82(23)$ & $203(27)$ \\
\hline
\end{tabular}

Mean age of menarche was 14.45 years in urban girls and 13.89 years in rural adolescents girls. It is evident from the table 1 that $5 \%$ of urban girls \& $2.8 \%$ rural girls reached (attained) menarche at the age of 11 or before $11.64 .2 \%$ of urban girls \& $74.1 \%$ of rural girls reported mean on set of menarche at the age of $12-14$ years where as $30.7 \%$ of urban \& $23 \%$ of rural girls reached (attained) menarche after 15 years of age. 
Menstrual Cycle Pattern among Adolescent School Girls in Chhattisgarh

Table 2. Source of Information of Menstrual cycle reported by respondents $(N=750)$

\begin{tabular}{|l|l|}
\hline Source & N (\%) \\
\hline Mother & $260(34.6)$ \\
\hline Sister & $126(16.8)$ \\
\hline Friend & $146(19.4)$ \\
\hline Teacher & $122(16.3)$ \\
\hline Relative & $39(5.2)$ \\
\hline Media (T.V) & $42(5.6)$ \\
\hline Books & $15(2.1)$ \\
\hline
\end{tabular}

Table 2 indicates that $69.3 \%$ girls had knowledge about menstruation before they achieved the menarche. The main source of information about menstruation cycle was mother (34.6\%) friend (19.4\%) sister (16.8\%) and from teacher, (16.3\%).while $12 \%$ of the girls reported to receive information from other sources ,relatives, media and books.

Table 3. Menstruation Pattern in Urban and Rural Adolescent girls

\begin{tabular}{|l|l|l|l|}
\hline Menstrual Classification & Urban (\%) & Rural (\%) & Total (\%) \\
\hline Cycle length & & & \\
\hline$<28$ & $34(8.7)$ & $18(5.2)$ & $52(6.9)$ \\
\hline $28-30$ & $247(62.8)$ & $265(74.4)$ & $512(68.6)$ \\
\hline $30-45$ & $108(27.2)$ & $73(20.3)$ & $181(23.7)$ \\
\hline $45-2$ M & $5(1.4)$ & 0 & $5(0.7)$ \\
\hline Duration of Menstruation in days & & & \\
\hline 3 to 5 days & $307(78)$ & $290(81.3)$ & $597(79.6)$ \\
\hline 6 to 7 days & $87(22)$ & $66(18.6)$ & $153(20.3)$ \\
\hline Blood Flow & & & \\
\hline Low & $9(2.2)$ & $19(5.2)$ & $28(3.7)$ \\
\hline Medium & $359(91.3)$ & $274(77)$ & $633(84.1)$ \\
\hline High & $26(6.5)$ & $63(17.7)$ & $89(12.1)$ \\
\hline & & &
\end{tabular}

$78 \%$ urban girls and 81.3\% rural girls reported 3-5 days blood flow during menstruation. 2.2\% urban girls reported low blood flow, 91.3\% medium blood flow and 6.5\% heavy blood flow, Where as 5.2\% rural girls had low blood flow, $77 \%$ had medium blood flow and $17.7 \%$ had heavy blood flow. Cycle length was shorter than $<28$ days in $8.7 \%$, between $28-30$ in $62.8 \%$ and longer than 30 days to 2 months in $28.6 \%$, in urban girls where as the cycle was shorter than $<28$ days in $5.2 \%$, between $28-30$ in $74.4 \%$ and longer than 30 days to 2 months in $20.3 \%$ in rural girls.

(C) The International Journal of Indian Psychology, ISSN 2348-5396 (e)| ISSN: 2349-3429 (p) | 94 
Menstrual Cycle Pattern among Adolescent School Girls in Chhattisgarh

Table 4. Prevalence of menstrual problems in Urban and Rural Adolescent Girls

\begin{tabular}{|l|l|l|l|l|l|}
\hline \multicolumn{4}{|l|}{ Menstrual Problem } & \multicolumn{3}{l|}{ Total (\%) } \\
\hline Urban(\%) & \multicolumn{1}{|l|}{ Rural(\%) } & Yes & No \\
\hline Yes & No & Yes & No & Yes & (38.2) \\
\hline $232(58.9)$ & $162(41.1)$ & $230(64.5)$ & $126(35.5)$ & $462(61.7)$ & $288(3.5)$ \\
\hline
\end{tabular}

Table 4 depicts prevalence of menstrual problems in urban and rural adolescents girls. It was observed that $58.9 \%$ and $64.5 \%$ urban and rural adolescents reported problems during menstrual cycle.

Table 5. Age wise Distribution of Menstrual Syndrome in Urban and Rural Adolescent Girls

\begin{tabular}{|l|l|l|l|l|l|l|l|l|}
\hline \multicolumn{4}{|l|}{ Menstrual Syndrome (Urban\%) } & \multicolumn{3}{l|}{ Menstrual Syndrome (Rural\%) } \\
\hline Age & $\begin{array}{l}\text { Abdominal } \\
\text { cramps/pain }\end{array}$ & Fatigue & $\begin{array}{l}\text { Food } \\
\text { cravings }\end{array}$ & Headaches & $\begin{array}{l}\text { Abdominal } \\
\text { cramps/ } \\
\text { pain }\end{array}$ & Fatigue & $\begin{array}{l}\text { Food } \\
\text { cravings }\end{array}$ & Headaches \\
\hline $\mathbf{1 2 +}$ & $13(43.3)$ & $7(23.3)$ & $6(20)$ & $4(13.3)$ & $10(33.3)$ & $6(20)$ & $9(30)$ & $5(16.6)$ \\
\hline $\mathbf{1 3 +}$ & $11(36.6)$ & $6(20)$ & $8(26.6)$ & $5(16.7)$ & $16(31.3)$ & $15(29.4)$ & $9(17.6)$ & $11(21.5)$ \\
\hline $\mathbf{1 4 +}$ & $27(56.2)$ & $5(10.4)$ & $8(16.8)$ & $8(16.6)$ & $13(32.5)$ & $7(20)$ & $9(22.5)$ & $10(25)$ \\
\hline $\mathbf{1 5 +}$ & $22(52.3)$ & $4(9.5)$ & $8(19)$ & $8(19)$ & $8(23.5)$ & $7(20.5)$ & $10(29.4)$ & $9(26.4)$ \\
\hline $\mathbf{1 6 +}$ & $16(45.7)$ & $7(20)$ & $7(20)$ & $5(14.2)$ & $14(41.1)$ & $10(29.4)$ & $7(20.5)$ & $3(8.8)$ \\
\hline $\mathbf{1 7 +}$ & $13(46.4)$ & $4(14.2)$ & $5(17.8)$ & $6(21.4)$ & $11(51.4)$ & $3(14.2)$ & $2(9.5)$ & $5(23.8)$ \\
\hline $\mathbf{1 8}+$ & $8(42.1)$ & $4(21)$ & $4(21)$ & $3(15.8)$ & $7(35)$ & $4(20)$ & $4(20)$ & $5(25)$ \\
\hline Total & $108(46.5)$ & $38(16.3)$ & $47(20.6)$ & $39(16.7)$ & $79(34.4)$ & $53(23)$ & $50(21.6)$ & $48(20.6)$ \\
\hline
\end{tabular}

Table 5 shows Menstrual Syndrome in urban and rural adolescents. It was observed that $46.5 \%$ of urban adolescents suffered abdominal cramps/pain, 20.6\% suffered food carvings, $16.3 \%$ suffered fatigue and $16.7 \%$ suffered from headache. In rural adolescents, $34.4 \%$ suffered abdominal cramps/pain, 23\% suffered fatigue, $21.6 \%$ suffered food carvings and $20.6 \%$ suffered headache as menstrual syndrome.

Table 6. Psychological of Symptoms of menstrual syndrome in Urban and Rural Adolescent Girls

\begin{tabular}{|l|l|l|l|l|l|l|}
\hline \multicolumn{1}{|l|}{ Symptoms } \\
\hline
\end{tabular}




\section{Menstrual Cycle Pattern among Adolescent School Girls in Chhattisgarh}

It is evident from table 6 that symptoms of depression was reported in $14.9 \%$, anxiety in $30.5 \%$ among urban girls, whereas among rural girls depression was noticed in $30.8 \%$, and anxiety in $27.2 \%$.

\section{DISCUSSION}

\section{The result of the present studies indicate that -}

1. Most of the adolescent girls received information about menstruation from their mothers (34.6\%)

2. $\quad 8.7 \%$ urban girls and $5.2 \%$ rural girls experienced menstrual cycle less than 28 days

3. 27.2\% urban girls and 20.3\% rural girls have reported menstrual cycle after 30-45 days.

4. Psychological problems experienced by rural girls was higher than the urban girls.

$65.8 \%$ of participants belonged to the age group 15-19 years while $34.2 \%$ were between age ranges of $10-14$ years. $90.5 \%$ of mothers of the study participants were literate.

The mean age of menarche at the adolescent school girls was 14.33 years whereas various studies conducted in Kalamboli the mean age at menarche was found to be 13.32 years, in West Bengal 12.8 years and in Turkey 12.81 years (Nemade et al. 2009, Dasgupta et al. 2008 \& Demir et al 2007).

Menstruation though a normal physiological process is many a time associated with menstrual disturbance. These disturbances may sometimes by very severe leading to loss of work during days.

In the present study 63.4\% girls had knowledge about menstruation, onset of menarche while in a study, 88.1\% girls had information regarding menstruation (Verma PB et al 2011). 61.29\% girls reported mother as a first source of information in a study,(Keerti Jogdand et al 2011) where as in present study $34.6 \%$ girls reported to receive information from mother.

In the present study, the inter menstrual interval was reported to be $<28$ days by $6.9 \%$ girls whereas it was $28-30$ days for $68.6 \%$ girls and more than $30-45$ days for $23.7 \%$ girls and more than 45 days -2 month on the for $0.7 \%$ girls. This could be because of changing trends in lifestyle, dietary habit, stress, hormonal imbalance or some medical imbalance or some medical reasons which requires gynecological assessment at the earliest. In a study conducted among tribal Gujjar adolescent girls, 9.9 percent of the subjects had their menstrual cycle between 45-60 days which is similar to the figure in the present study (Dhingra et al 2009).

66.7\% girls had regular cycles, $84.1 \%$ had medium blood flow, 78.7\% had cycle length between 21 to 35 days \& $79.7 \%$ had bleeding for 3 to 5 days in the present study that is similar to the study conducted by Dambhare et al. 2012, which reported 69.52\% had cycle length \& 67.56\% girls had cycle length of 21-35 days and duration of flow for 2 to 4 days. Present study, in the conformity with other study (Keerti Jogdand et al 2011) which reported $76.65 \%$ girls had 


\section{Menstrual Cycle Pattern among Adolescent School Girls in Chhattisgarh}

duration of flow for 3-5 days. A study reported $84 \%$ girls having blood flow between 3-5 days (Balsubramanian, 2005). In a study conducted at Malaysia 88.2\% girls had menstrual flow for 37 days and 62.8\% had cycle length between 21-35 days (Lee et al 2006).

In the present study $61.7 \%$ girls had ever faced menstrual problem, abdominal cramps/pain being the most common (40.5\%). In other studies $60.77 \%$ (study in central India by Dharampal et al 2012) \& 50.6\% girls reported dysmenorrheal among girls ( Verma et al. 2013). In the present study 51.5\% girls reported menstrual syndrome with headache ( $18.3 \%)$, depression (36.3\%), anxiety (28.8\%), fatigue (20.1\%), food cravings (21.1\%), similar results have been reported in a study (Sheetu et al. 2014) which found 51.5\% girls to have premenstrual syndrome with headache (50\%), depression (47.8\%), tension (36.9\%), abdominal cramps (35.5\%) being the common symptoms. Result of the present study is also in conformity with the study conducted by (Dambhare et al 2012). which showed 56.15\% girls had experienced headache (26.7\%) which was the most common symptom. Menstrual symptoms was experienced by $74.6 \%$ and dysmenorrheal by $67.7 \%$ of the adolescent girls in a study (Lee et al 2006) and the most common problem was dysmenorrheal $88.8 \%$ as reported in his study .

\section{CONCLUSION \& RECOMMENDATIONS}

The findings provide a base line data for planning awareness programmes for the adolescent girls. Results indicate that adolescent girls experience menstrual problems. The natures of menstrual problems are different. The percentage of urban girls experiencing psychological problem is higher and the percentage of rural girls experiencing psychosomatic problem is high.

\section{ACKNOWLEDGEMENT}

We are also thankful to the adolescent girls of Chhattisgarh for their cooperation and participation in the study.

\section{REFERENCE}

Adam HPJ (2002). Menstruation in young girls: A clinical prospective. Obst. Gynecol., 99(4); 655-662.

Ailbereisen RK, Kracke B (1997). In: Health risks and developmental transitions during adolescence. Schulenberg J,

Balasubramanian P; Health needs of poor unmarried adolescent girls-A community based study in rural Tamil Nadu. Indian Journal of Population Education, 2005:18-33.

Dambhare DG, Wagh S, Dudhe J; Age at Menarche \& Menstrual cycle pattern among school Adolescent girls in Central India. Global Journal of Health Science, 2012; 4(1): 105-11.

Dasgupta, A. \& Sarkar, M. (2008). Menstrual Hygiene: How Hygienic is the Adolescent Girl? Indian Journal of Community Medicine, 33 (2), 77-80. http://dx.doi.org/10.4103/09700218.40872 


\section{Menstrual Cycle Pattern among Adolescent School Girls in Chhattisgarh}

Demir, S. C., Kadayifci, T. O., Vardar, M. A., et al. (2000). Dysfunctional uterine bleeding and other menstrual problems of secondary school students in Adana, Turkey. J Pediatr Adolesc Gyecol, 13 (4), 171-5. http://dx.doi.org/10.1016/S1083-3188(00)00061-9

Dhingra, R. \& Anil Kumar. (2009). Knowledge and Practices Related to Menstruation among Tribal (Gujjar) Adolescent Girls. Ethno-med, 3 (1), 43-48.

Diaz A, Laufer MR, Breech L (2006). Menstruation in girls and adolescents: Using the menstrual cycle as a vital sign. Pediatrics, 118(5); 2245-2250.

Govt. of India; National Health Profile, Percent distribution of population by age and sex, Ministry of Health and. Family Welfare, New Delhi, 2010.

Jogdand K, Yerpude P; A community based study on menstrual hygiene among adolescent girls. IJMCH, 2011; 13(3): 2-6.

Kaplowitz P (2006). Pubertal development in girls: Secular trends. Curr. Opin. Obstet. Gynecol., 18(5): 487-491.

Kaprio J, Rimpelä A, Winter T, Viken RJ, Rimpelä M, Rose MJ (1995). Common genetic influences on BMI and age at menarche. Hum. Biol., 67: 739-753.

Lee LK, Chen PCY, Lee KK, Kaur J; Menstruation among adolescent girls in Malaysia: a crosssectional school survey. Singapore Med J., 2006; 47(10): 869.

Maggs JL, Hurrelmann K, editor. Cambridge, Cambridge University Press; 1997. Self-reported maturational timing and adaptation in adolescence, pp. 85-10

Namade, D., Anjenaya, S., \& Gujar, R. (2009). Impact of health education on knowledge and practices about menstruation among adolescent school girls of Kalambolo, NaviMumbai. Health and Population: Perspectives and Issues, 32 (4), 167-175.

Okusanya BO, Garba KK, Okome GB, Ohiosimuan O (2009). Menstrual pain and associated factors amongst undergraduates of Ambrose Alli University, Ekpoma, Edo State, Nigeria. Niger. J. Med., 18(4): 409- 412.

Padez C (2003). Age at menarche of schoolgirls in Maputo, Mozambique. Ann. Hum. Biol., 30(4): 487-495.

Rebacz E (2009). Age at menarche in schoolgirls from Tanzania in light of socioeconomic and socio demographic conditioning. Coll. Antropol., 33(1): 23-29.

Sheetu M K, Naik J D, Thakur M S, Langre S D, Pandey V O; Patterns \& Problem of Menstruation amongst and Adolescents girls Residing in the Urban Slum. Sch.J.App. Med. Sci., 2014; 2 (2A) : 529-534.

Thomas F, Renaud F, Benefice E, de Meeus T, Guegan JF (2001). International variability of ages at menarche and menopause: Pattern and main determinants. Hum. Biol., 73(2): 271-290.

Verma PB, Pandya CM, Ramanuj VA, Singh MP; Menstrual pattern of adolescent school girls of Bhavnagar, Gujarat. NJIRM, 2011; 2(1): 38- 40.

How to cite this article: P Srivastava, A Varoda, R Venugopal (2016), Menstrual Cycle Pattern among Adolescent School Girls in Chhattisgarh, International Journal of Indian Psychology, Volume 3, Issue 3, No. 10, DIP: 18.01.182/20160303, ISBN: 978-1-365-19879-3 